ON THE

\section{ANESTHETIC PROPERIIES}

OF THE

\section{LYCOPERDON PROTEUS,}

oR

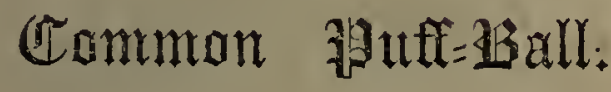

$\mathrm{BY}$

\section{BENJAMIN W. RICHARDSON.}

(Read before the Medical Society of London, on. Saturdey, May 20th, 185.2.)

REPRINTED FROAI THE "ASSOCLATION MEDICAI, JOURAA".

\section{LONDON :}

PRINTED BY T. RICHARDS, 3\% GREAT QUEEN STREET.

1853. 



\section{ON THE ANAESTHETIC PROPERTIES OF THE LYCOPERDON PROTEUS, OR COMMON PUFF-BALL.}

A FEW months since, I had a conversation with my friend Mr. Henry Hudson, a Leicestershire surgeon, on the management of bees; and was particularly interested in his description of an old, and, as I now find, very prevalent custom, of stupifying these insects with the smoke of the fungus known under the name of puff-ball, before extracting the contents of the hive. By this stupifying process, the bees, I was told, could be rendered inactive and insensible for several minutes; but that they all recovered eventually in the most perfect manner, and that the cruel practice of destroying them with the fumes of sulphur was thus avoided.

This practice of rendering bees insensible by inhalation is so much like the modern plan of producing narcotism in men and animals by ether and chloroform, that my mind very naturally seized the analogy; and I was induced to perform a series of experiments on animals with the fungus. 
My first experiment was made on the 28th of last March. A kitten was placed in a bell-shaped glass vessel, open at bottom and top. Smoke from a pice of the fungus ignited was allowed to rise pretty freely into the bell; but several interruptions occurred, so that thirty-five minutes elapsed before any positive effect took place. By that time, however, the creature was fairly narcotized: a cut in the ear produced no sign of pain. The breathing was reduced to eight respirations per minute, and the temperature of the body was lowered. From time to time, after removal from the bell, I counted the breathing and the heart-beat, and found them gradually increasing in number, and the body becoming warmer. The sleep, however, was profound; and, after a period of two hours, no sign of sensibility to pain could be elicited. I laid the animal down by the side of her mother, and in the morning found her skipping about as well as ever.

The second experiment was performed on a dog. It was placed in a box, in which it had sufficient room to turn round, and in which the atmospheric air could enter freely from the top. The smoke of the fungus was admitted through the bottom of the box, and the animal was fairly narcotized in a quarter of an hour. On removing it on to a table in the narcotized state, a deep puncture was made in the nose: blood of a bright red colour flowed freely, but no sign of pain was given. The symptoms that preceded the narcotism were those of intoxication; the animal turned round several times; power in the legs ceased; and it fell down at last on its side, insensible; the bowels acting involuntarily. For five minutes after the anæsthesia had come on, the respirations numbered forty-eight per minute; but the heartsounds were steady, and comparatively slow; the first sound corresponding to each inspiration. The body was warm. Five minutes later, there was a convulsive fit; but 
the body was still insensible, and the pulse forty per minute. The pupil was dilated and fixed, but the head was drawn back when a light was brought near to the eye. Three minutes later, the animal was becoming conscious, and wagged its tail when spoken to, but showed no pain when pricked with a knife. At a quarter past nine, it commenced to wince when pinched, and crawled about in a reeling manner. From this time, the recovery was rapid; and in ten minutes the creature seemed as well as though nothing had been done to it.

In a third experiment, at which Dr. Crisp was present, a dog was again the subject. There were the same symptoms of intoxication, but complete narcotism set in in six minutes. In this case, the narcotizing agent had been given more freely and steadily than in the previous cases. Eighteen minutes after removal from the box, the animal remained insensible to pain, but was conscious when spoken to. Blood drawn from the nose was of a bright red colour. The other symptoms were very similar to those described in the last experiment. Two minutes later, rallying commenced; and in twenty minutes the creature had quite recovered. We remarked, that the sensibility returned in the fore legs previous to returning in the hinder ones.

Finding that the impure fumes of the burning fungus were rather painful to breathe, as they produced some degree of irritation in the throat, and caused the eyes to water, I made them pass through a solution of caustic potash, previous to exposing the animal to their influence. This was easily done. The smoke, being produced in a large closed vessel, was forced by water-pressure through a Wolff bottle containing a solution of caustic potash, and was received in an inverted glass bell. I thus obtained a perfectly clear gas, free from carbonic acid. A young cat was now placed under the bell; she became slightly convulsed in thirty. 
seconds, and was profoundly narcotized in two minutes. The heart-beats were not much affected, and recovery took place in seven minutes after removal from the vessel.

This experiment was performed on the 13th of April; and on the following day I repeated the experiments, both with the impure and clarified vapour, in the presence of Dr. Willis and Dr. Cormack, with complete success.

Mr.Sampayo, a gentleman residing in Barnes, had a favourite dog, which was very old, was constantly troubled with cough, and had a large and painful tumour over the abdomen. As the owner of the dog wished to have this tumour removed, Dr. Willis thought there would be a good opportunity for trying the anæsthetic power of the fungus during an operation. He therefore kindly undertook to cut out the growth, if I chose to produce narcotism. I did so with the impure smoke of the fungus. The animal was narcotized in six minutes; and the operation, which occupicd ten minutes, was done without the merest sign of pain until the last suture was being put in, when wincing took place. Neither the heart nor the respirations secmed much affected in this instance. The recovery was so rapid, that, in six minutes, it would have been impossible to tell, without previous knowledge of the fact, that the animal had been subjected either to narcotism or operation.

I need not occupy time in giving the details of several more similar experiments; I will, therefore, refer only to a few others, which are of special interest.

On several occasions I have given the narcotizing vapour in limited quantities, and for a long time. This dilution of the narcotic has been effected either by mixing the clarified fumes of the fungus with a large quantity of atmospheric air, or by using a preparation of the fungus, which has been deteriorated by charring it, as I think, and which is sold in the shops under the name of "prepared fungus for fumigat-. 
ing bees". In this diluted shape, the narcotic produces a modified class of symptoms. Narcotism is induced very slowly, the animal reeling for a long time, and seeming to be paralysed, without being altogether free from pain. Convulsions, too, and vomiting, are apt to come on, and the animals recover gradually, but surely. I experimented on three animals, in the presence of Dr. Snow, in which these results followed. One of the animals vomited; and in all the cases, the anæsthesia, though sufficiently marlied, was not so perfect as in some other instances. By continuing the exhibition of the narcotic, however, we succeeded in destroying a rablit. The symptoms which the very diluted fumes of the fungus produce in animals, are somewhat like the effects of tobacco in persons who are not accustomed to smoke, with the addition of more decided narcotism and insensibility. It is worthy of remark, that an animal can be made to tolerate this narcotic by inhaling it freenently. I liave a dog on which I have experimentod from the first. Originally, the creature would come under the influence of the narcotic in six minutes; she will now inhale it, in liberal proportions, for an hour, at the end of which time she is intoxicated, and vomits if she has had a meal previously; but she is quite conscious, answers to her name, and tries to walk; the sensibility of the body being absent altogether, and the limbs occasionally convulsed. It requires a space of half-an-hour for her to recover from this condition. I have noticed that young animals, whose respirations are quick, although rapidly narcotized by a large dose of the substance, resist the action of a diluted dose very obstinately. I have kept young kittens for more than an hour in the vapour, and, under its influence, rolling about in the most drunken manner, but not absolutely insensible ; when, however, complete narcotism does set in, it continues for a long period. 
It occurred to me to give the narcotic in connexion with oxygen gas: the fungus was therefore burned in oxygen, and the dense fumes produced were clarified by caustic potash, and were passed into the glass bell, together with some free oxygen. A young cat was placed under the bell : she became uneasy in thirty seconds, and was fairly narcotized in a minute and a half. On removing her from the glass, the respirations were forty-six per minute, and the insensibility of the body was perfect. She recovered in four minutes, and ran out of the room.

It was a matter of some importance to ascertain if the narcotic principle of the fumes of the fungus would be given up to any fluid substance through which they might be passed. Yesterday, therefore, the fumes arising from the burning fungus, mixed with a large quantity of atmospheric air, were first driven through caustic potash, and then, in this diluted state, were passed, through alcohol, into a glass bell. A kitten placed under the bell soon became uneasy, at the end of an hour was taken out insensible, and recovered slowly.

I have intentionally destroyed a great many animals with the narcotic, in order to observe how it would produce death. The respirations fail in a gradual and progressive manner, until they cease altogether, and the breathing sounds are dry and loud. The pupil is usually dilated and fixed for several minutes previous to absolute death. The temperature of the body sinks slowly. The heart continues to beat quickly for some time after respiration has ceased. The blood is always red, and generally not readily coagulable; but in a cat which had breathed oxygen gas with the narcotic, it coagulated with great rapidity. The lungs are of a pale or pink colour, never congested, nor is there congestion of any other internal organ. The heart is empty of blood in most cases; and its contractions may be excited for long intervals of time. The respiratory muscles 
and the bowels may also be excited to motion for a long period after the body is laid open. In four kittens which I opened before respiration ceased, I saw the rhythmical action of the heart, and regular respiratory acts, for twenty-five minutes after the opening. The peristaltic action of the bowels remained for not less than forty minutes. In no case have I found the brain and spinal chord congested, or in any degree visibly affected. Cadaveric rigidity soon becomes very marked.

On the table before the Society there lies a full-grown dog, which has this day been destroyed by the fumes of the fungus. The body is laid open for the inspection of the Fellows. The animal was placed in a box filled with the impure fumes of the burning fungus. It was fairly narcotised in ten minutes. As I did not wish it to recover, I kept it in the vapour five minutes longer, and then found the respirations to be eleven per minute, and the heart-beats sixty; the pupils a little dilated, and fixed; the body warm. I continued to expose it to the action of the fumes for fifteen minutes more, when it was removed from the box. It was less warm, but there were still six respirations per minute, and the heart was beating steadily, with both sounds distinct. It was as insensible to pain as if really dead, and the body was flaccid. The pupil was fixed. Red blood flowed from the ear on puncture. I have not the shadow of a doubt that the animal would have recovered from this prolonged narcotism, had I kept it from the narcotic influence ; for the respirations were increasing while I was taking the above observations. I returned it to the box; in five minutes more the respirations ceased, the heart-beats continuing for some minutes later. The blood was fluid; the lungs, and all the other internal organs, were free from congestion, and the heart was pretty firmly contracted. 
The fumes of the fungus, when clarified with caustic potash, and diluted pretty freely with atmosphere, are not unpleasant to breathe. On Thursday, I inhaled them myself in this form, for four minutes. They produced decided symptoms of stupor; the pulse was excited, and I was glad to sit down. These effects, however, passed off in three minutes, and I felt none the worse, except that the throat was somewhat irritated, and the voice a little hoarser.

My experiments would not have heen complete, without having given some of the fungus itself to an animal as food. I have done so to two dogs, without effect. In one case, a large quantity of the fungus was cut up, and boiled in milk, and the milk was given to a dog. No narcotism or other effect followed. On a second occasion, a piece of the fungus ( $\ni \mathrm{i}$ ) was chopped up with beef, and given to a hungry dog. The animal swallowed the mess greedily, but showed no sign of injury. Withering states, on the authority of Marsigli, that the puff-ball is fried with salt in Italy, and is eaten as food; and I am told by Mr. Butler, the herbalist, in Covent Garden (from whom the fungus can be obtained), that he has eaten it himself when fried; and that Mr. Smith, the well known statiorer in Long Acre, esteems it a great delicacy, and eats it regularly when in season (in autumn).

To sum up the results of these experiments: there is, it is evident, a principle in the fumes of the puff-ball capable of causing anæsthesia in animals. The physiological effects brought out by this anæsthetic are also very marked. In a liberal dose, it narcotises rapidly and effectually, without unpleasant symptoms; and the narcotic effect soon passes off, leaving the animal in perfect health. In diluted doses, it produces intoxication and convulsions ; is longer in causing anæsthesia ; sometimes excites cough and vomiting, and leaves the animal for a long time stupid and unwell. When it is carried to the extreme, the respira- 
tions cease before the beat of the heart. Indeed, in observing animals under influence of the narcotic, it is only necessary to watch the respiratory movements ; if these remain, even though reduced to the lowest, the animal will certainly recover on removing it from the cause of the narcotism. In this respect the narcotic principle of the fungus resembles the Woorali poison.

Experiments with the fungus may be performed in various ways. If the impure smoke is to be used, it is only necessary to let it pass freely into a box, through a hole in the bottom. A large tin funnel fixed beneath the box in an inverted position will readily convey the smoke. The box having been filled with the smoke, the animal is placed in it, and the lid is laid lightly on. Nacotism will generally take place in eight or ten minutes, often sooner.

To clarify the fumes arising from the fungus, two small tin funnels are made to fit mouth to mouth, and the nozzle of one funnel is connected with a Wolff hottle containing a solution of caustic potash. Another tube, connected with the Wolff bottle, will convey the clarified fumes away. If, now, a piece of the fungus be placed in a burning state between the funnels, the smoke can either be drawn by the mouth from the exit tube of the bottle through the ordinary double valve apparatus for chloroform, or it can be driven over into a bell jar, by fixing the nozzle of a pair of bellows to the free end of the funnels, and blowing gently. The glass bell into which the vapour is received should be placed on a nicely fitting board, and the animal must be passed into the bell quickly, after it is charged with the narcotic vapour.

Some one, perhaps, will ask, What is the nature of the narcotic principle contained in the fumes of the fungus? Is it a product or an educt of combustion? On this subject I have no direct information. That several of the fungi do 
possess a narcotic principle, has long been known; but no analysis has as yet thrown much light on the subject. In some countries fungi are used for making intoxicating potions. Our very distinguished countryman, Dr. Alfred Taylor, in the second edition of his valuable Manual of Medical Jurisprudence, thus remarks on the fungi :

"Most of the narcotic irritant poisons, just considered, owe their deleterious effects to the presence of an alkaloidal principle similar to morphia, and susceptible of insulation by complex chemical processes. There is, however, considerable difficulty in extracting these alkaloids from the respective vegetables; and when extracted, the chemical differences among them, in respect to the action of tests, are so slight, as to be scarcely appreciable, even in the hands of a practised analyst."

The few conclusions, therefore, which it is in my power to offer with regard to this subject, are very insignificant ; and are derived more from physiological observation than from chemical inquiries. However, they had better be stated.

I. The narcotic principle is given off freely during the combustion of the fungus; and, as it exists in the fumes produced, is highly volatile.

II. Combustion of the fungus in oxygen gas does not destroy the anæsthetic principle.

III. The anæsthetic principle is not quickly absorbed or destroyed, either by water, alcohol, or strong alkaline solutions.

I present these researches to the profession with great deference. I am aware that they are not so extensive as they ought to be, but they have cost me many weeks of incessant labour; and I put them forth as being calculated to lead to further inquiry into the narcotic effects of the fungi, by other and abler minds, rather than from an estimation of their own value. I have been desirous only to show that 
there is a principle in one of the fungi capable of producing narcotism in animals by inhalation. It remains to be seen, whether other plants of the same family possess similar powers; and whether a narcotic agent can be obtained from a fungus that shall admit of being employed in practice with no more trouble to the operator, and with less danger to the patient, than are entailed by the anrsthetic agents now in use. So important a subject is at least worthy of further investigation.*

Mortlake, London, May 31.st, 1853.

* I return my deepest acknowledgments for many valuable suggestions, and much kind interest, to Drs. Willis, Cormack, Snow, and Crisp, to Mr. Thos. Taylor, and to Mr. Henry Hudson. I have also to thank my friends, Messr's. Leipner and Beresford, for the practical assistance they have rendered me in my experiments. And lastly, I am exceedingly grateful to the Fellows of the Medical Society for the kind manner in which they received this paper. 

